\title{
Saccular otolith mass asymmetry in adult flatfishes
}

\author{
D. V. Lychakov*ף, Y. T. Rebane†, A. Lombarteß, \\ M. Demestre $\S$ and L. A. Fuiman \\ *Sechenov Institute of Evolutionary Physiology and Biochemistry of Russian Academy of \\ Sciences, St Petersburg, Thorez pr., 44, 194223, Russia, \$Ioffe Physical Technical \\ Institute of Russian Academy of Sciences, Politekhnicheskaya 26, St Petersburg 194021, \\ Russia, §Departament de Recursos Marins Renovables, Institut de Ciències del \\ Mar-CMIMA (CSIC), Passeig Marítim 37-49, 08003 Barcelona, Catalonia, Spain and \\ ||Department of Marine Science, University of Texas at Austin, Marine Science Institute, \\ 750 Channel View Drive, Port Aransas, TX 78373-1267, U.S.A.
}

(Received 29 June 2007, Accepted 20 February 2008)

\begin{abstract}
A dimensionless measure of otolith mass asymmetry, $\chi$, was calculated as the difference between the masses of the right and left paired otoliths divided by average otolith mass. Saccular otolith mass asymmetry was studied in eight flatfish species (110 otolith pairs) and compared with data from a previously published study on roundfishes. As in the case of symmetrical fishes, the absolute value of $\chi$ in flatfishes does not depend on fish length and otolith growth rate, although otolith mass and the absolute value of otolith mass difference are correlated with fish length. The values of $\chi$ were between $-0 \cdot 2$ and $+0 \cdot 2$ in $96 \cdot 4 \%$ of flatfishes studied. The mean \pm S.E. value of $\chi$ in flatfishes was significantly larger than in standard bilaterally symmetrical marine fishes ('roundfishes'), respectively $0.070 \pm 0.006$ and $0.040 \pm 0.006$. The most prominent distinction is the existence of downside prevalence of saccular otolith mass in flatfishes, which contrasts with no right-left prevalence in roundfishes found in a previous study. In the righteyed flatfishes (Soleidae), the left saccular otoliths are heavier than the right otoliths. In the lefteyed flatfishes (Bothidae and Citharidae), the right saccular otoliths are heavier than the left otoliths. Not all flatfishes, however, fit in this design: $11.8 \%$ of flatfishes studied had the heavier saccular otoliths in the upside labyrinth and $5.4 \%$ of flatfishes had no otolith mass asymmetry (within the accuracy of the analysis). At the same time, the more mobile flatfishes (bothids and citharids) have more symmetrical and, hence, more precisely organized saccular otolith organs than the bottom-associated flatfishes (soleids). It is possible to assume that the value of the otolith asymmetry is not only correlated with flatfish placement in a particular family, or position of eyes, but also may correlate with general aspects of their ecology. Mathematical modelling indicated that for most flatfishes one-side saccular prevalence had no substantial significance for sound processing. On the other hand, calculations showed that $49 \%$ of flatfishes (but only $14.5 \%$ of roundfishes) have $|\chi|$ which exceed the critical level and, in principle, could sense the difference between the static displacement of the large and small paired otoliths. At that, the number of the soleids that could sense this difference is greater than the number of the bothids and citharids, 84 and $27 \%$, respectively.

(C) 2008 The Authors
\end{abstract} Journal compilation (C) 2008 The Fisheries Society of the British Isles

Key words: flatfishes; mathematical modelling; morphometry; saccular otolith.

$\dagger$ Author to whom correspondence should be addressed. Tel.: +7 812 5504989; fax: +7 812 5523012; email: Lychakov@iephb.ru 


\section{INTRODUCTION}

Otolith mass asymmetry may be responsible at least partly for both space illusionary sensations and space motion sickness in human subjects and abnormal behaviour when fishes are subjected to weightlessness during parabolic or space flight (Egorov \& Samarin, 1970; Hoffman et al., 1977; Von Baumgarten et al., 1982). Mathematical modelling has shown that acoustic functionality (sensitivity, temporal processing and sound localization) of a fish can be altered by otolith mass asymmetry due to incompatibility and incongruity of the right and left otolith movements (Lychakov \& Rebane, 2005). There are some extreme values of otolith asymmetry in fishes (Lychakov, 1996; Lychakov et al., 2006). Obviously, to avoid the detrimental effects due to mass discrepancy, a large otolith asymmetry must be accommodated by the central nervous system or at the macular level. The questions arise: what degree of otolith asymmetry does have an affect on the functioning of otolith organs? Does the natural otolith asymmetry have substantial implication for sound and vestibular processing for most fishes?

Teleosts are well-suited biological models for assessing the physiological role of otolith mass asymmetry because the compact otoliths can easily be quantitatively assessed. Otolith mass asymmetry was studied in 811 otolith pairs of 77 bilaterally symmetric teleost species (roundfishes) (Lychakov et al., 2006). Mathematical modelling has indicated that for most roundfishes, otolith mass asymmetry is well below critical values, so that most roundfishes do not experience functional impairment as a result of otolith mass asymmetry (Lychakov \& Rebane, 2005; Lychakov et al., 2006). In contrast to roundfishes, otolith asymmetries have been reported in flatfishes (Nolf, 1985; Campana, 2004; Helling et al., 2005). These asymmetries seem at first glance quite natural because flatfishes (Order Pleuronectiformes) have the most asymmetric shape and lateralized behaviour of any fishes. During their metamorphosis, flatfishes undergo a $90^{\circ}$ tilt to the right or left side to become bottom-adapted animals (Platt, 1973; Graf \& Baker, 1990; Schreiber, 2006). At the same time, the otolith organs do not rotate within the skull, as the eyes do, and retain their individual structural orientation relative to the dorsal fin (Fig. 1) (Platt, 1973; Sogard, 1991). It is possible to assume that the otolith asymmetries revealed in adult flatfishes, may have as yet unknown adaptive significance.

The aims of the present study were to quantify otolith mass asymmetry in a large number of flatfishes and to model its influence on auditory and vestibular functions. Because the flatfish sacculi are involved in both hearing and gravity (vestibular) perception (Chapman \& Sand, 1974; Graf \& Baker, 1990) only this organ was chosen for investigation.

\section{MATERIALS AND METHODS}

Data used in the analysis were collected from eight species of adult Pleuronectiformes from the Catalan coast (north-western Mediterranean) caught with an epibenthic dredge (Table I). All fishes were obtained in experimental trawl cruises; all fishes were dead when they arrived on board. Experimental procedures for extracting and preparing otoliths for the study were published previously (Lombarte \& Morales-Nin, 1995; Lombarte et al., 2006) and are briefly described here. Standard lengths $\left(L_{\mathrm{S}}\right)$ were 
(a)

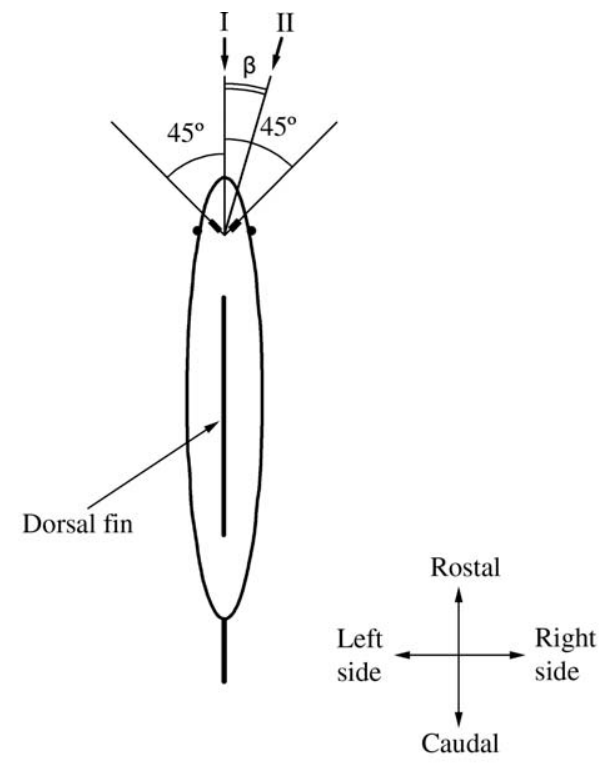

(b)

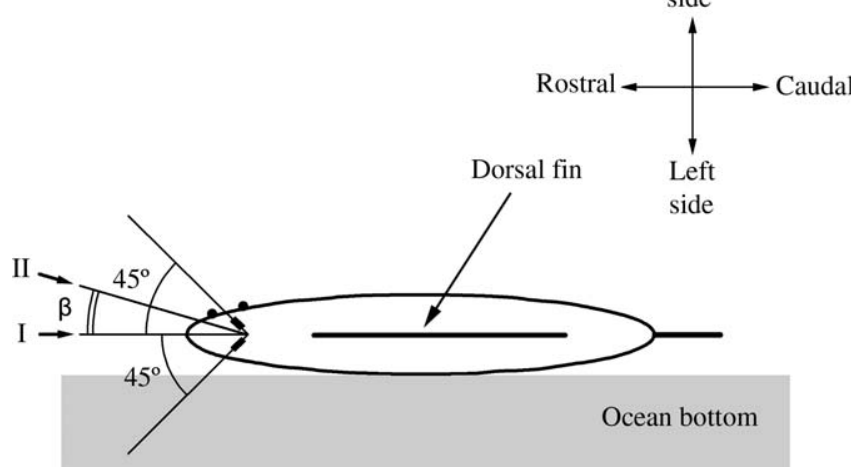

FIG. 1. Schematic drawings of (a) the premetamorph flatfish larva from a top view and (b) adult righteyed flatfish from a side view (not to scale). The premetamorph flatfish larva is pelagic with dorsal fin upright, and with lateralized eyes. The adult flatfish lies on the left side (blind-side) with dorsal fin horizontal, and both eyes are on the right side (eyed-side). The saccular otoliths are in the conventional morphological position relative to the dorsal fin in premetamorph and adult flatfishes. Right and left saccular otoliths are represented as short black strips. They deviate from the midsagittal plane of the fish by an angle $45^{\circ} . \beta$ is an angle between the longitudinal axis of the fish and the axis of stimulation. I and II correspond to the situation such that the sound direction (arrow) is coincident or not with the longitudinal axis of the fish.

measured from the tip of the snout to the base of the tail prior to removal of otoliths. After dissection of the auditory capsules, saccular otoliths were removed from each side, rinsed in distilled water, air-dried at room temperature for several days and then weighed on an OHAUS (Pine Brook, NJ, U.S.A.) analytical plus balance with a precision of $0.0001 \mathrm{~g}$. For comparison, previously collected data from marine fishes $(74$ species, 608 saccular paired otolith) were used (Lychakov et al., 2006). 


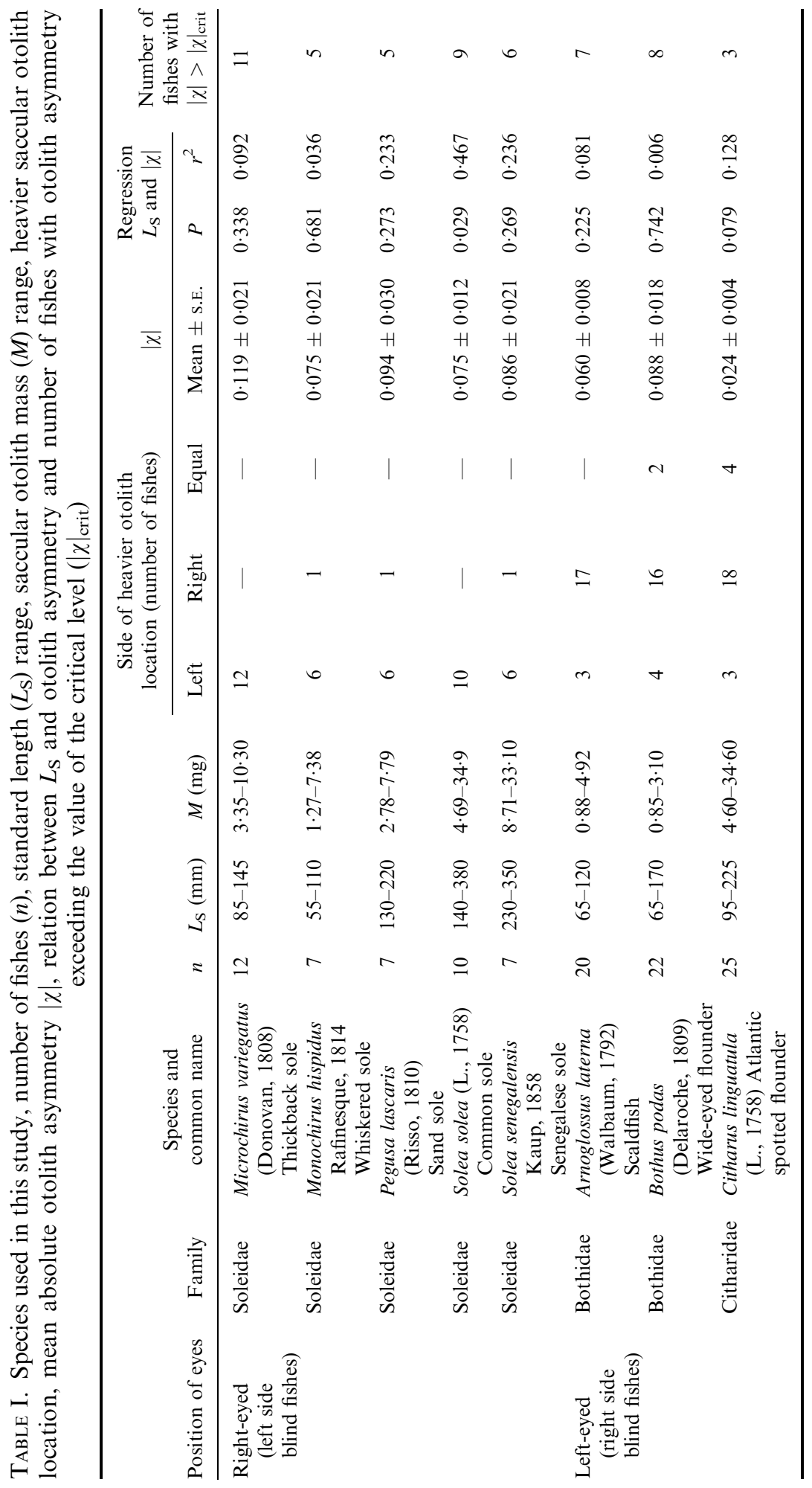


The dimensionless otolith mass asymmetry $(\chi)$ was calculated from: $\chi=\left(M_{\mathrm{R}}-M_{\mathrm{L}}\right)$ $M^{-1}$, where $M_{\mathrm{R}}$ and $M_{\mathrm{L}}$ are the otolith masses of the right and left paired otoliths and $M$ is the mean mass of the right and left paired otoliths.

Theoretically $\chi$ can change from -2 to 2 , and $\chi=0$ corresponds to the absence of mass asymmetry $\left(M_{\mathrm{R}}=M_{\mathrm{L}}\right)$, whereas $\chi=-2$ or $\chi=2$ corresponds to the maximal asymmetry (absence of one otolith). A positive sign of $\chi$ means that the right otolith mass is larger than the left paired otolith mass and a negative sign means the reverse situation. The absolute value of otolith mass asymmetry, $|\chi|$, is the value without a sign, i.e. $|-0.02|=0.02$ and $|+0.02|=0.02$. The relationship between a species' $\chi$ and its otolith growth rate was also examined. The species' otolith mass asymmetry $|\chi|_{\text {species }}$ was calculated as the average of individual values of $|\chi|$ for each species. To evaluate otolith growth rate the relationship between otolith mass and $L_{\mathrm{S}}, M=b \cdot L_{\mathrm{S}}+a$, where $b$ is the coefficient characterizing the growth rate of the otolith and $a$ is a constant (intercept) for the given species.

Mathematical models were applied for analyses of otolith displacements with regard to the otolith mass asymmetry and otolith mass under sound stimulation or gravity (Lychakov \& Rebane, 1993, 2000, 2004, 2005). Mathematical analyses were based on a number of biophysical assumptions denoted previously and four morphological otolith rules (Lychakov \& Rebane, 1993, 2000). The basic equation, which describes otolith centre-of-gravity motion, was the equation for pendular oscillations (De Vries, 1950; Lychakov \& Rebane, 1993, 2000).

To reveal the role of otolith mass asymmetry on auditory functions, the equation of motion for the otolith centre-of-gravity interacting with a plane sinusoidal wave propagating along the $x$-axis within limits of the direct stimulation mechanism was considered (Fay \& Popper, 1980; Rogers et al., 1988; Lychakov \& Rebane, 1993, 2000). The $x$-axis coincides with the long axis of ellipsoid-shaped otolith when the effect of otolith mass asymmetry is modelled on sound sensitivity and temporal processing and with the longitudinal axis of the fish when the effect of otolith mass asymmetry is modelled on sound localization.

Modelling the effect of otolith mass asymmetry on sound sensitivity was based on the assumption that the asymmetric otoliths move different distances, when subjected to a plane sinusoidal acoustic wave (the model has been detailed in Lychakov \& Rebane, 2005). Due to the difference between oscillation amplitudes, the sensitivity of right and left otolith organs must be different. Generally, the greater $|\chi|$ and $M$ are, the higher the difference between oscillation amplitudes of paired otoliths $\left(\Delta A_{x \mathrm{RL}}\right)$ and the higher difference in sensitivity between right and left paired otolith organs at frequencies around which the otolith amplitude displacements are maximal $\left(v_{\max }\right)$ (Lychakov \& Rebane, 2005). Note, that the sensitivity of the otolith organ is defined as the otolith displacement amplitude relative to the macula, per unit displacement of the water and the fish's body (Lychakov \& Rebane, 2000). Thus, with a knowledge of $\Delta A_{x \mathrm{RL}}$, it is possible to model the effect of otolith mass asymmetry on sound sensitivity.

Modelling of the effect of otolith mass asymmetry on temporal processing was based on the assumption that the asymmetric otoliths move in different time patterns, when subjected to the plane sinusoidal acoustic wave (the model has been detailed in Lychakov $\&$ Rebane, 2005). Due to the phase shift $(\varphi)$ the left and right paired otoliths attain their maximal displacement at different points in time. Generally, the greater $M$ and $|\chi|$ are, the higher the value of $\varphi$ and the higher time difference at frequencies particularly around $v_{\max }$ (Lychakov \& Rebane, 2005). The phase shift does not depend on the amplitude of the displacement of the water and fish's body within the acoustic field (Lychakov $\&$ Rebane, 2005). Thus, calculating $\varphi$, it is possible to model the effect of otolith mass asymmetry on time difference when the left and right paired otoliths attain their maximal displacement.

Finally, the effect of otolith orientation and mass asymmetry on sound localization was modelled. Consideration of this modelling must be prefaced by a brief account of some features of interaction of the ellipsoid-shaped saccular otoliths in roundfishes with a plane sinusoidal wave (Lychakov \& Rebane, 2005). The principal roundfish model is based on the following facts and assumptions: (1) the direction of a plane sinusoidal 
wave and the fish's longitudinal axis are parallel to the horizontal plane, (2) $\chi$ equals zero, i.e. $M_{R}=M_{L}$, (3) the saccular macula is nearly planar, perpendicular to the horizontal plane and deviates $c .45^{\circ}$ from the fish's mid-sagittal plane [Fig. 1(a)] (Dale, 1976; Fay \& Popper, 1980; Lu et al., 1998), (4) the physiological response of the sacculus is a cosine function of the angle between the plane of the macula and the axis of stimulation (Fay \& Popper, 1980; Sand, 2002), (5) the macula physiological response is linear with otolith displacement (Hudspeth \& Corey, 1977; Ohmori, 1987) and (6) the modelling does not take into account a role of the diversity of saccular hair cell orientations on the macula. Based on these facts and assumptions, the previously elaborated mathematical model has shown that if the sound direction is coincident with the longitudinal axis of the fish, i.e. $\beta=0^{\circ}$ [situation I; Fig. 1(a)], the difference between the right and left otolith displacements will be zero. Hence, the physiological responses of both sacculi will be equal. If the sound direction deviates from the longitudinal axis of the fish, i.e. $\beta \neq 0$ [situation II; Fig. 1(a)], the difference between the right and left otolith displacements is not zero. In this case, as calculated by Lychakov \& Rebane (2005), for every angle $\beta$ there is a unique value of the difference between the right and left paired otolith displacements and, respectively, unique difference between physiological responses of right and left sacculi. Using this unique physiological difference, the roundfishes can determine the azimuth of sound direction but with $180^{\circ}$ ambiguity and for given amplitude of plane sinusoidal wave. It must be stressed that if the direction of the plane sinusoidal wave is coincident with the mid-sagittal plane of the fish, the otolith displacements of the right and left paired otoliths and physiological responses of both sacculi will be equal for all sound directions. Thus, the roundfishes cannot use the difference between the right and left saccular otolith displacements for effective determination of elevation of sound direction.

The existence of mass differences between the right and left paired saccular otolith can pose some problems for sound localization (Lychakov \& Rebane, 2005). If, for example, the right otolith is heavier, the otolith displacements and physiological responses are asymmetrical, and the right side response will be greater than left side (Lychakov \& Rebane, 2005). The asymmetric response pattern in a fish with the right otolith mass prevalence is identical in shape and amplitude to the response pattern in other fish without otolith mass asymmetry but as if the sound direction had been biased to the right side (Lychakov \& Rebane, 2005). In the other words, if the sound direction is parallel to the fish's longitudinal axis, it will appear to a fish with right otolith mass prevalence that the sound source is situated at the right angle to its longitudinal axis. Generally, the greater $M$ and $\chi$ are, the higher the value of the apparent deflection angle, $\beta_{a}$, between the true and perceived sound directions (Lychakov \& Rebane, 2005).

Based on these assumptions and considerations, the roundfish mathematical model was applied to flatfishes, but with regard to the unique orientation of their saccular otoliths.

To reveal the role of otolith mass asymmetry on vestibular function we used the mathematical model of the response of the ellipsoid-shaped otolith to the action of gravity (Lychakov \& Rebane, 2000, 2004).

\section{RESULTS}

\section{MORPHOMETRIC MEASUREMENTS}

In all flatfishes taken together, $96 \cdot 4 \%$ of values of $\chi$ were between $-0 \cdot 2$ and $+0 \cdot 2$. The mean \pm S.E. value of $|\chi|$ was $0 \cdot 070 \pm 0 \cdot 006, n=110$. The mean values of $|\chi|$ for individual species are given in Table I. For comparison purposes, data for flatfishes taken together and previously collected data for marine fishes (Lychakov et al., 2006) were compared. According to a two-sample $t$-test the mean \pm S.E. value of $|\chi|$ in flatfishes was significantly larger than in marine roundfishes: $0 \cdot 070 \pm 0 \cdot 006, n=110$, for flatfishes, and $0 \cdot 040 \pm 0 \cdot 006, n=608$, for marine roundfishes $(P<0.05)$. 
According to the regression analysis, in all fishes taken together there was no relationship between $L_{\mathrm{S}}$ and $|\chi|(P>0.05)$ (Fig. 2). The results of the regression analysis for individual species are given in Table I. The regression of $|\chi|$ on $L_{\mathrm{S}}$ was significant only for the common sole Solea solea (L.) $|\chi|=0 \cdot 003 \cdot L_{\mathrm{S}}+$ $0 \cdot 1532\left(L_{\mathrm{S}}\right.$ in $\left.\mathrm{cm}\right)(P<0 \cdot 05, n=10)$.

For all flatfish species, with the exception of thickback sole Microchirus variegatus (Donovan), there was an obvious linear correlation between $M$ and $L_{\mathrm{S}}$. The mean \pm S.E. $r^{2}$ for all eight species studied had a high value $0.78 \pm 0.09$, $n=8$. The regression analysis showed that there was no relationship between otolith growth rate, $b$ and $|\chi|_{\text {species }}(P>0.05, n=8)$.

According to the regression analysis, in all flatfishes taken together there was a relationship between $L_{\mathrm{S}}$ and otolith mass difference, $|\Delta|(P<0.001)$.

Thus, in the majority of flatfishes studied (96.4\%) irrespective of $L_{\mathrm{S}}$ and position of the eyes, saccular otolith mass asymmetry was low, $|\chi|<0 \cdot 2$. There was no relationship between $L_{\mathrm{S}}$ and absolute value of saccular otolith mass asymmetry $\chi$. The value of the saccular otolith mass asymmetry $|\chi|$ does not depend on otolith growth rate. On the other hand, otolith mass and otolith mass difference correlated with $L_{\mathrm{S}}$.

In the majority of right-eyed (left side blind) Pleuronectiformes (Table I), the left saccular otoliths were heavier than the right otoliths (Fig. 3). According to the Wilcoxon sign rank test and sign test, the preferred location of the heavier otolith on the blind side of the fish was significant $(P<0 \cdot 001)$. The mean \pm S.E. value of $\chi$ for all right-eyed fishes taken together was $-0.078 \pm 0.012, n=43$. The mean value of $|\chi|$ was $0.092 \pm 0.009, n=43$. In the majority of left-eyed (right side blind) Pleuronectiformes (Table I), the right saccular otoliths were heavier than the left otoliths (Fig. 4). According to the Wilcoxon sign rank test and sign test, the preferred location of the heavier otolith on the blind side of the fish was significant $(P<0.001)$. The mean \pm s.E. value of $|\chi|$ for all

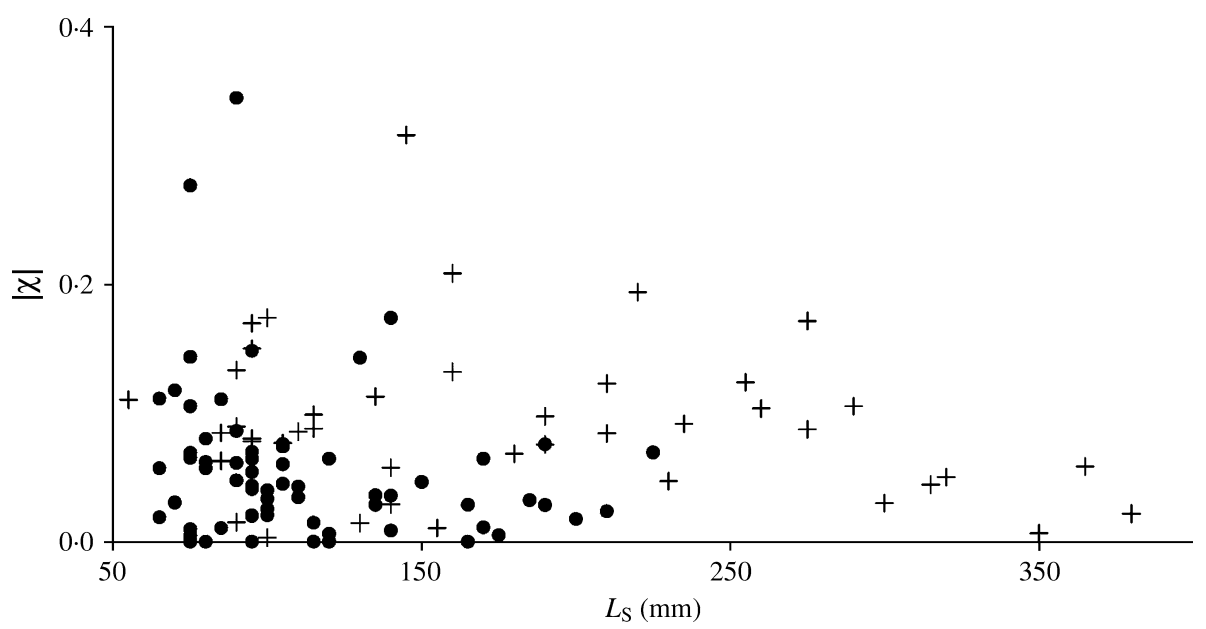

FIG. 2. Saccular otolith mass absolute asymmetry $|\chi|$ in Pleuronectiformes and standard length $\left(L_{\mathrm{S}}\right)$ [O, left-eyed (right side blind) fishes; + , right-eyed (left side blind) fishes]. 


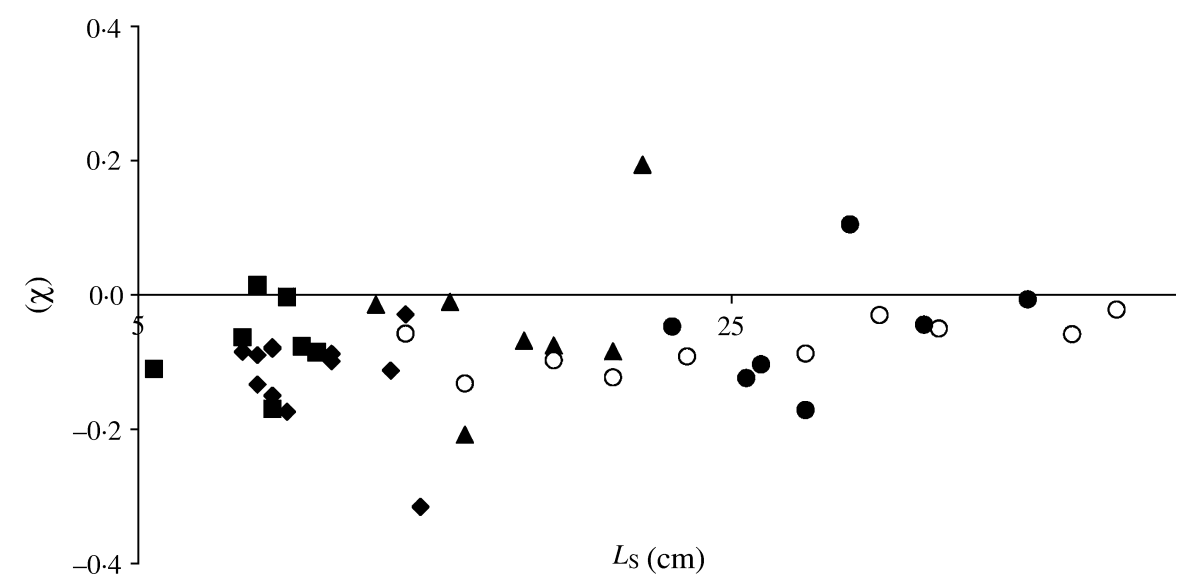

FIG. 3. Saccular otolith mass asymmetry $(\chi)$ in right-eyed (left side blind) Pleuronectiformes and standard length $\left(L_{\mathrm{S}}\right)(\diamond$, Microchirus variegatus; $\mathbf{\square}$, Monochirus hispidus, $\mathbf{\Delta}$, Pegusa lascaris; $\bigcirc$, Solea solea; Solea senegalensis).

left-eyed fishes taken together was $0.044 \pm 0 \cdot 008, n=67$. The mean \pm s.E. value of $|\chi|$ is $0 \cdot 056 \pm 0 \cdot 007, n=67$. According to a two-sample $t$-test the mean value of $|\chi|$ in right-eyed flatfishes (Soleidae; Table I) taken together was significantly larger than in left-eyed flatfishes (Bothidae and Citharidae; Table I) $(P<0 \cdot 01)$.

Similar results were obtained for otolith asymmetry of individual fish species. According to the Wilcoxon sign rank test and sign test, the preferred location of the heavier otolith on the blind side of the fish was significant $(P<0 \cdot 05)$ for the right-eyed soleids, $M$. variegatus and $S$. solea, and all left-eyed bothids and citharids: scaldfish Arnoglossus laterna (Walbaum), wide-eyed flounder Bothus podas (Delaroche) and Atlantic spotted flounder Citharus linguatula (L.) (Table I).

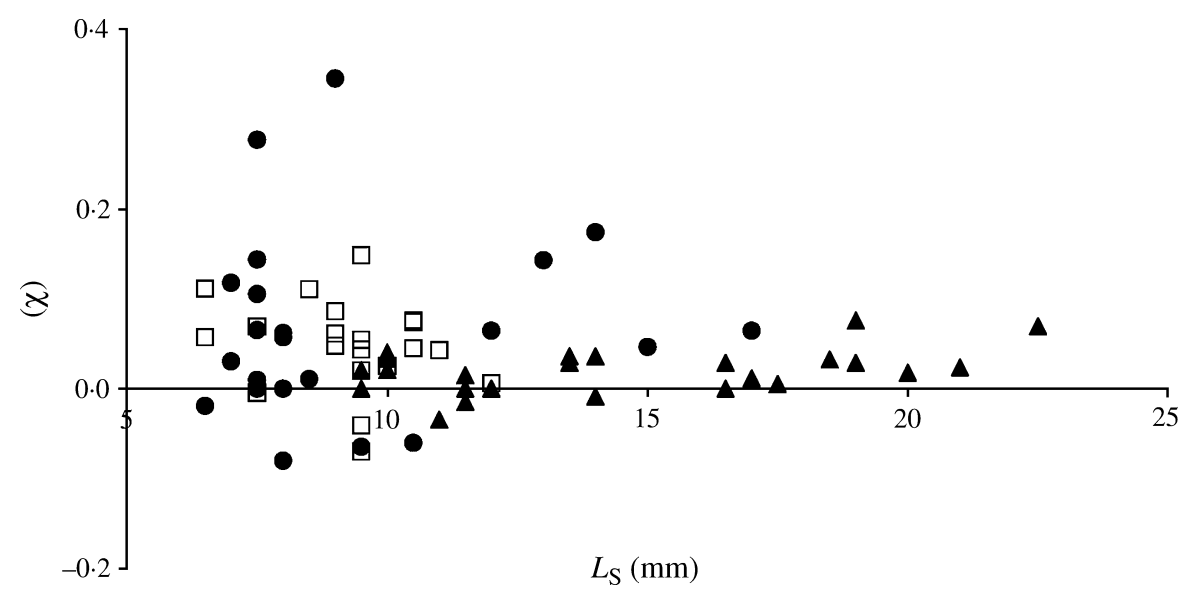

FIG. 4. Saccular otolith mass asymmetry $(\chi)$ in left-eyed (right side blind) Pleuronectiformes and standard length $\left(L_{\mathrm{S}}\right)(\square$, Amoglossus laterna;, Bothus podas; $\mathbf{\Delta}$, Citharus linguatula). 
According to the Wilcoxon sign rank test, the preferred location of the heavier otolith on the blind side of the fish was significant $(P<0.05)$ for the right-eyed soleids, whiskered sole Monochirus hispidus Rafinesque sand sole Pegusa lascaris (Risso) and senegalese sole Solea senegalensis Kaup (Table I). According to the sign test, however, the preferred location was not significant $(P>0 \cdot 05)$ for these three species.

Thus, in the majority of right-eyed (left side blind) flatfishes, the left saccular otoliths are heavier than the right otoliths (Table I and Fig. 3). In the majority of left-eyed (right side blind) flatfishes, the right saccular otoliths are heavier than the left otoliths (Table I and Fig. 4). There are exceptions, however (Table I and Figs 3 and 4). Certain flatfishes (13 of 110 studied or $11.8 \%$ ) have the heavier saccular otoliths in the eyed-side labyrinth. Other flatfishes (six of 110 studied or $5 \cdot 4 \%$ ) have no otolith mass asymmetry (within the accuracy of the measurement).

\section{OTOLITH MODELLING}

When modelling the effect of otolith mass asymmetry on sound sensitivity it was assumed that the difference between otolith amplitudes must be greater or close to the value of the threshold stimulus displacement of $0.0002-0.0005 \mu \mathrm{m}$ (Chapman \& Sand, 1974; Lu et al., 1998). If it is assumed that threshold stimulus displacement is strictly specified and equal to $0.0002 \mu \mathrm{m}$ and because $96.4 \%$ of fishes studied have $|\chi|<0 \cdot 2$ and the maximal value of $M=34.85$ $\mathrm{mg}$ (Table I), for the maximal values $\chi=0.2$ and $M=40 \mathrm{mg}$ the value of $\Delta A_{\mathrm{xRL}}=0.00005 \mu \mathrm{m}$. For lighter otoliths and smaller $|\chi|$, the values of $\Delta A_{x \mathrm{RL}}$ are substantially smaller. For a hypothetical sole with $M=100 \mathrm{mg}$ and $|\chi|=$ 0.2 (the $L_{\mathrm{S}}$ of such sole would be of $950 \mathrm{~mm}$ ), the value of $\Delta A_{x \mathrm{RL}}=0.00007$ $\mu \mathrm{m}$. Thus, at the strictly specified threshold stimulus displacement, the right and left sacculi will send practically indistinguishable signals in the brain. This means that around the threshold stimulus displacement the flatfishes studied are not subjected to one-side deafness.

Using the previously elaborated equation (Lychakov \& Rebane, 2005) the time difference when the left and right paired otoliths attain their maximal displacement was calculated. For the mean otolith mass asymmetry $|\chi|=0 \cdot 070$ and mass range of $40-100 \mathrm{mg}$, the time difference varied from 0.0009 to $0.0012 \mathrm{~s}$. These time intervals are less than the minimum broadband-pulsed sound period resolved by the fish auditory system of 0.0015 s (Wysocki \& Ladich, 2002). If $|\chi|=0 \cdot 2$, the time difference varies from 0.0025 to $0.0035 \mathrm{~s}$ for the same mass range of $40-100 \mathrm{mg}$.

To reveal the role of otolith mass asymmetry on sound localization the apparent deflection angle, $\beta_{a}$, was calculated. The angle between the long axis of the macula and the longitudinal axis of the fish $\alpha$ is $45^{\circ}$ (Platt, 1973). Using the equation of Lychakov \& Rebane (2005) for $|\chi|=0 \cdot 070, \alpha=45^{\circ}$ and a mass range from 40 to $100 \mathrm{mg}, \beta_{a}$, varies from $2 \cdot 8$ to $3 \cdot 3^{\circ}$ at frequencies around $v_{\max }$. If $|\chi|=0 \cdot 2, \beta_{a}$ varies, accordingly, from $8 \cdot 1$ to $9 \cdot 3^{\circ}$. These angels are smaller than minimum resolvable angles of the fish auditory system (Chapman \& Johnstone, 1974; Schujf \& Buwalda, 1980). 
To reveal the role of otolith orientation on sound localization the roundfish mathematical model was applied to flatfishes, but with regard to the unique orientation of their saccular otoliths [compare Fig. 1(a), (b)]. 'The flatfish saccular otolith (sagitta) on both sides lies at roughly $45^{\circ}$ to the dorso-ventral axis' (Platt, 1973). In other words, when a flatfish lies on the ocean bottom, both paired saccular otoliths and corresponding maculae lie at $45^{\circ}$ to the bottom [Fig. 1(b)]. The angle between the planes in which saccular otoliths lie opens forward (rostrally) and equals $90^{\circ}$. Taking into consideration the model outlined above (details provided by Lychakov \& Rebane, 2005), the effective difference between the right and left paired saccular otolith displacements can occur if the axis of sound stimulation vector lies not in the horizontal but in the vertical plane, that is, perpendicular to the ocean bottom [Fig. 1(b)]. Therefore, when a flatfish lies on the bottom, its saccular otoliths are best suited to determine not the azimuth but the elevation of the sound direction [Fig. 1(b)].

The value of the difference between the displacements of the large and small paired otoliths can be calculated. This depends on the value of the otolith mass asymmetry under the action of the force of gravity. Consider a fish is motionless and with dorsal fin upwards, i.e. a resting fish is perpendicular to the ocean bottom. Under these conditions, the influence of the otolith mass asymmetry on the difference between the otolith displacements will be maximal and easily calculated.

In this situation the value of the final displacement of the saccular otolith relative to macula under the action of the force of gravity is given by the equation (Lychakov \& Rebane, 2004): $x=g 0 \cdot 030563 \cdot M_{\mathrm{R}}{ }^{0.3644}$, where $x$ is the final otolith displacement $(\mu \mathrm{m}), g$ is the acceleration of gravity $\left(9 \cdot 8 \mathrm{~ms}^{-2}\right)$ and $M_{\mathrm{R}}$ is the mass of the right otolith $(\mathrm{mg})$. An analogous equation can be written for the left otolith.

The equation for the difference in the final displacement of the large and small otoliths under the action of gravity is (Lychakov \& Rebane, 2004):

$$
\Delta x=\mathbf{g} 0 \cdot 030563 \cdot M_{\min }^{0 \cdot 3644}\left(\Omega^{-0.3644}-1\right)
$$

where $\Delta x$ is the difference between final displacements $(\mu \mathrm{m})$ of the large and small saccular paired otoliths, $M_{\min }$ is the mass $(\mathrm{mg})$ of the smaller saccular otolith, $\Omega$ is the ratio of small, $M_{\min }$, and large, $M_{\max }$, saccular otoliths.

Setting the difference between final displacements of the large and small paired otoliths $\Delta x$ (equation 1) equal to the value of the threshold otolith displacement, $0.01 \mu \mathrm{m}$ (Goldberg \& Fernández, 1975), the expressions for the critical level of the otolith mass ratio are obtained: $\Omega_{\text {crit }}=\left(1+0 \cdot 033387 M_{\min }{ }^{-0.3644}\right)^{-2.7442}$.

It is possible to convert $\Omega$ to $|\chi|$ and express $M_{\min }$ in terms of $M$ and $\chi \Omega=$ $(2-\chi)(2+|\chi|)^{-1}$ and $M_{\min }=0 \cdot 5 M \cdot(2-|\chi|)$.

The critical level curve, $|\chi|_{\text {crit }}$ curve, for the sacculus and observed values of $|\chi|$ for Pleuronectiformes and for marine roundfishesare shown in Figs 5 and 6 . If the observed value of the otolith mass asymmetry exceeds the value of the critical level, i.e. $|\chi|>|\chi|_{\text {crit }}$, the fish will feel the difference between the displacements of the large and small paired otoliths. If the observed otolith mass 


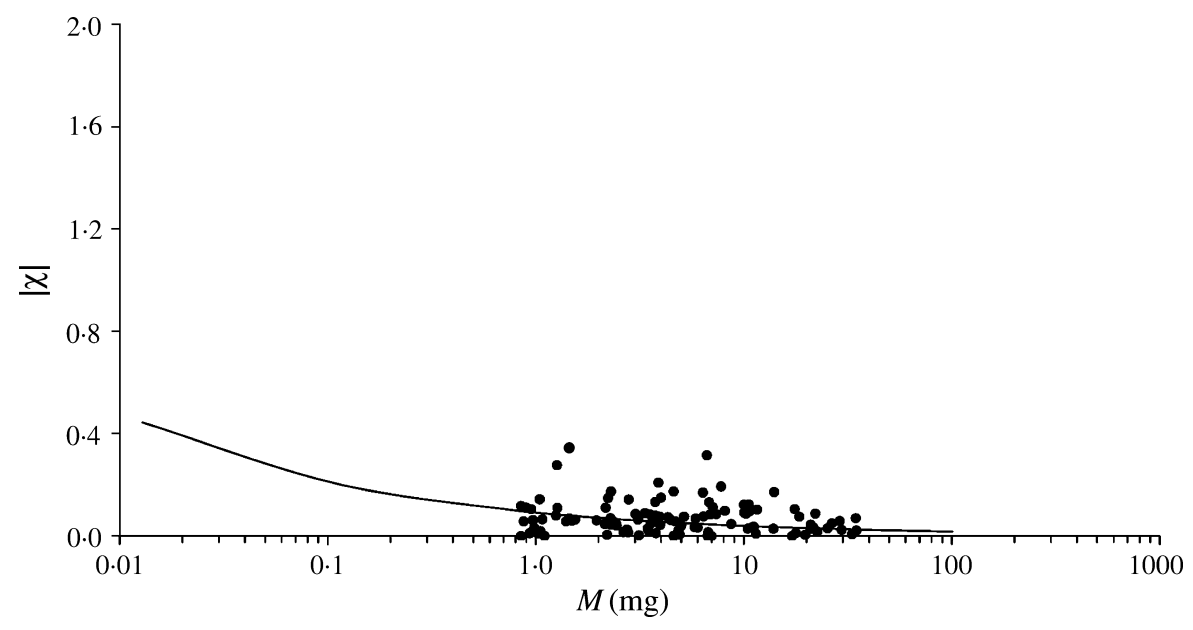

FIG. 5. Relationship between critical saccular otolith mass asymmetry $\left(|\chi|_{\text {crit }}\right)$ and observed values of otolith mass asymmetry $(|\chi|)$ in Pleuronectiformes and mean otolith mass $(M$; mean of the right and left paired otolith masses). If $|\chi|_{\text {crit }}<0 \cdot 3$, the curve (-) for $|\chi|_{\text {crit }}$ is fitted by $y=0 \cdot 0916 x-0 \cdot 3644$ with an accuracy of $0.5 \%$.

asymmetry is smaller than the value of the critical level, i.e. $|\chi|<|\chi|_{\text {crit }}$, the fish will not distinguish the difference between the displacements of the large and small paired otoliths. Calculation shows that 54 flatfishes studied $(49 \%)$ had $|\chi|>|\chi|_{\text {crit }}$ and 56 fishes $(51 \%)$ had $|\chi|<|\chi|_{\text {crit }}($ Fig. 5). The 520 marine roundfishes (85.5\%) had $|\chi|<|\chi|_{\text {crit }}$ and 88 fishes (14.5\%) had $|\chi|>|\chi|_{\text {crit }}$ (Fig. 6). According to the Mann-Whitney rank $U$-test, the distribution of $|\chi|$ relative to $|\chi|_{\text {crit }}$ curve for flatfishes (Fig. 5) differed significantly $(P<0 \cdot 01)$ from distribution of $|\chi|$ relative to $|\chi|_{\text {crit }}$-curve for marine roundfishes (Fig. 6).

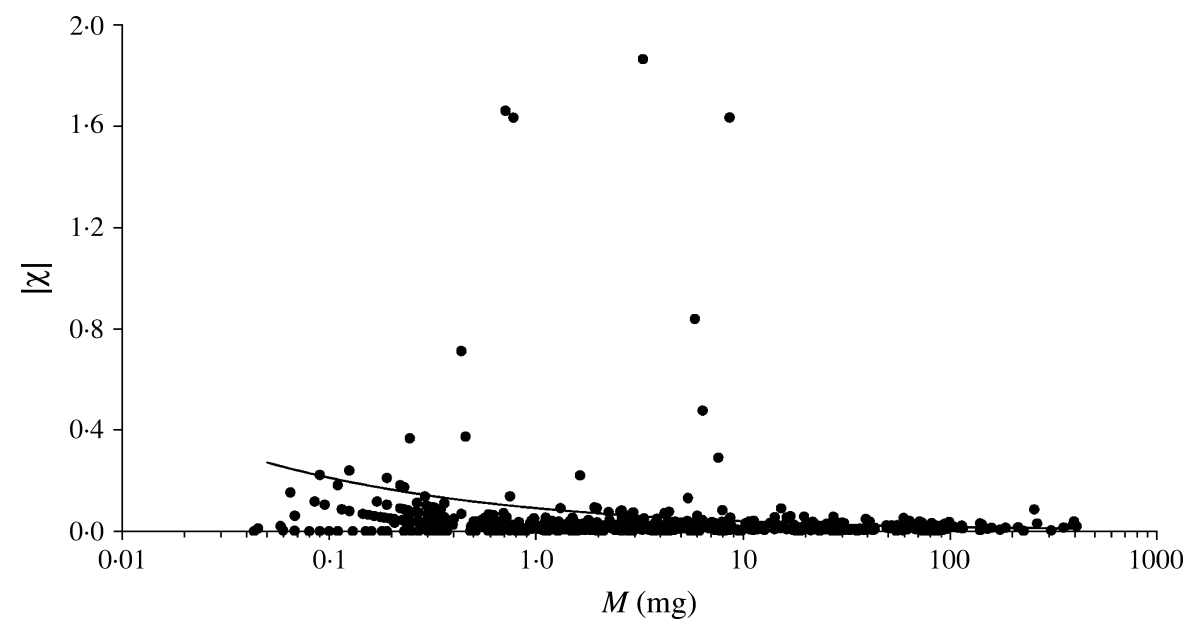

FIG. 6. Relationship between critical saccular otolith mass asymmetry $\left(|\chi|_{\text {crit }}\right)$ and observed values of otolith mass asymmetry $(|\chi|)$ in roundfishes and mean otolith mass $(M$; mean of the right and left paired otolith masses). If $|\chi|_{\text {crit }}<0 \cdot 3$, the curve (-) for $|\chi|_{\text {crit }}$ is fitted by $y=0 \cdot 0916 x-0 \cdot 3644$ with an accuracy of $0.5 \%$. 
The results for individual flatfish species are shown in Table I. According to the Wilcoxon sign rank test and sign test, in $84 \%$ of right-eyed soleids the otolith mass asymmetry exceed the value of the critical level (36 of 43 fishes, $P<$ 0.001). These fishes will feel the difference between the displacements of the large and small paired otoliths. In contrast, only $27 \%$ of the left-eyed bothids and citharids have an otolith mass asymmetry, which exceeds the value of the critical level (18 of 67 fish, $P<0.01$ ).

\section{DISCUSSION}

There are some similarities and distinctions, with respect to otolith mass asymmetry characteristics, between the marine roundfishes (Lychakov et al., 2006) and flatfishes (present study). In both types of fishes, the degree of the saccular otolith mass asymmetry $|\chi|$ does not depend on fish length or otolith growth rate. In both groups, otolith mass, $M$, and otolith mass difference, $|\Delta|$, are correlated with $L_{\mathrm{S}}$. In the majority of marine roundfishes and flatfishes, the values of $\chi$ are between $-0 \cdot 2$ and $+0 \cdot 2$, respectively, in $97 \cdot 5$ and $96 \cdot 4 \%$ of fishes. On the other hand, the mean value of $|\chi|$ in flatfishes is significantly larger than in marine roundfishes $(0.070 \pm 0.006$ and $0.040 \pm 0.006$, respectively).

The most prominent difference between these types of fishes is the existence of one-sided prevalence of otolith mass asymmetry in flatfishes (this study) and no right-left prevalence in roundfishes (Lychakov \& Rebane, 2004, 2005; Lychakov et al., 2006). In total, however, $11 \cdot 8 \%$ of flatfishes have the heavier saccular otoliths in the eyed-side labyrinth and $5 \cdot 4 \%$ of flatfishes have no otolith mass asymmetry (within the accuracy of the measurement).

It is not known at what stage of flatfish ontogeny one-sided saccular otolith asymmetry develops. Mathematical modelling has shown that in roundfishes the value and sign of $\chi$ are stable during a fish's lifetime (Lychakov et al., 2006). This is also probably true for flatfishes but with one principal provision. Flatfishes are unusual among fishes in that they 'metamorphose abruptly into fish that swim on one side, and lie on the ocean floor' (Schreiber, 2006). It is reasonable to assume that during metamorphosis the 'natural' otolith growth is subjected to different influences which make possible the development of otolith asymmetry (for example, due to asymmetry of blood supply for the eyedside and blind-side otolith organs). Thus, flatfish otolith growth appears to be governed not only by genetic factors, but it may also be modified during flatfish metamorphosis. These two patterns superimpose on one another and give not only the one-sided otolith asymmetry but also account for the strong scatter of $\chi$ in flatfishes (compare Figs 5 and 6). If one-sided otolith asymmetry is only a by-product of flatfish metamorphosis, then it is clear why soleids, which are much more bottom-associated than bothids or citharids (Ostroumova, 1971), have significantly larger mean value of $|\chi|$, respectively, 0.092 and 0.056 . It suggests that it is vital for the more mobile flatfishes to have more symmetric otolith organs than for less mobile species. Because of 'resistance' against otolith asymmetry lateralization, the number of 'deviations' (when the eyed-side otoliths are heavier than the blind-side otoliths) is more in bothids or citharids than in soleids, respectively, 23.9\% (16 of 67 fishes) and $7 \%$ (three of 43 fishes). On average, the more mobile flatfishes have more 
symmetrical and, hence, more precisely organized saccular otolith organs. Hence, it is possible to assume that the value of otolith asymmetry is not only determined by taxonomic position (family) or position of eyes, but it also may correlate with aspects of their ecology. In roundfishes, there were no apparent differences in $\chi$ between benthic and littoral fishes and pelagic fishes (Lychakov et al., 2006). Similar results were obtained for otolith asymmetry of individual fish species studied (Lychakov et al., 2006).

Helling et al. (2005) found that in the right-eyed plaice Pleuronectes platessa L. there is no significant mass difference between right and left saccular otoliths. Otolith mass asymmetry for the paired saccular otoliths is distributed around zero (Helling et al., 2005). In the left-eyed turbot Psetta maxima (L.) the saccular otoliths in the right blind-side labyrinth are significantly heavier (Helling et al., 2005). Sogard (1991) found that in the juvenile winter flounder Pseudopleuronectes americanus (Walbaum) there was no significant tendency for the length of the saccular otoliths on one side to be large than the other.

On the other hand very prominent mass and morphological asymmetries were shown in a left-eyed flatfish Psetta maeotica (Pallas) $\left(L_{\mathrm{S}}=55 \mathrm{~cm}\right)$ (Lychakov, 1996). In the left labyrinth there were two otoliths designed as a sandwich. The upper otolith looked like an ornate buckle (Lychakov, 1996). The lower, macular, otolith adjacent to the first otolith had an ordinary shape (Lychakov, 1996). The combined mass of these two left otoliths was $79 \cdot 05 \mathrm{mg}$. The right otolith had ordinary shape and mass of $116.58 \mathrm{mg}$. Hence, $\chi=0 \cdot 3837$. This large asymmetry probably occurred through pathology (Lychakov, 1996). This conclusion is consistent with otolith morphometric data (Sogard, 1991; Helling et al., 2005; present study) and 'gross morphology' results (Platt, 1973). In cleared specimens of speckled sand-dab Citharichthys stigmaeus Jordan \& Gilbert and diamond turbot Hypsopsetta guttulata (Girard) there was no obvious asymmetry in size and orientation between the right and left otoliths (Platt, 1973). In addition, examination of transverse sections of whole heads indicated the bilateral symmetry of the otolith organs of adult California halibut Paralichthys californicus (Ayres) (Platt, 1973).

Thus, the majority of flatfishes have the blind-side prevalence of saccular otolith mass asymmetry but it is rather small (c. 7\%). In some flatfishes the blind-side prevalence is absent or the eyed-side otoliths can be heavier than the blind-side otoliths. To reveal the significance of this small downside otolith mass prevalence otolith displacement was modelled under sound stimulation or gravity.

Before proceeding further, recall that the sacculi in standard bilaterally symmetric teleosts are the primary hearing receptors (Popper \& Carlson, 1998). Though flatfishes are not hearing specialist, they are sensitive to sounds (Chapman \& Sand, 1974; Popper \& Fay, 1993). Beside, there is good reason to believe that sound reception in flatfishes involves the saccular otolith organs (Chapman \& Sand, 1974). On the other hand, it is shown that flatfish sacculi have a major role in tilt responses (Platt, 1973). 'The sacculus-lagena is both necessary and sufficient for ocular compensation responses to lateral tilt' (Platt, 1973). Thus, the flatfish saccular otolith organs are involved in both hearing and gravity (vestibular) perception (Chapman \& Sand, 1974; Graf \& Baker, 1990). 
Mathematical modelling has shown that only fishes that contain the largest otoliths and $|\chi|>0 \cdot 2$ could have difficulties with sound processing due to incompatibility and incongruity of the right and left otolith movements (Lychakov \& Rebane, 2005). In the overwhelming majority of standard bilaterally symmetric teleost otolith mass asymmetry is within the range of $-0 \cdot 2<\chi<+0 \cdot 2$ or $<20 \%$, and nearly $85 \%$ of symmetric fishes had $|\chi|<0 \cdot 05$. (Lychakov \& Rebane, 2004, 2005; Lychakov et al., 2006). Thus, for most roundfishes, otolith mass asymmetry is well below critical values, so that most fishes avoid functional hearing impairment caused by otolith mass asymmetry.

The mean value of $\chi$ in flatfishes is significantly larger than in marine roundfishes. Calculations, however, show that for the mean otolith mass asymmetry $|\chi|=0.070$ and deliberately extended mass range of 40-100 mg (compare with measured otolith masses in Table I) saccular otolith asymmetry does not affect discrimination of threshold stimulus, temporal processing or sound localization. The large otolith mass asymmetry $|\chi|>0 \cdot 2$, which in principle can result in sensory losses, occurred in only two of 110 fishes $(1 \cdot 8 \%)$. Thus, theoretically, for most flatfishes one-sided saccular prevalence has no substantial implications for sound processing. These fishes have no need to compensate for the otolith asymmetry.

To reveal the role of otolith mass asymmetry on vestibular function the mathematical model of the response of the ellipsoid-shaped otolith to the action of the force of gravity was used (Lychakov \& Rebane, 2000, 2004). The value of the difference between the static displacement of right and left ellipsoid-shaped otoliths was calculated depending on otolith mass asymmetry. This displacement difference can be the main source of the different discharge characteristics of the paired otolithic organs and hence the functional otolith asymmetry. The calculation showed that $49 \%$ of flatfishes and only $14.5 \%$ of marine roundfishes have the otolith mass asymmetry in excess of the critical level $|\chi|>|\chi|_{\text {crit }}$. Thus, about a half of flatfishes and only $15 \%$ of standard bilaterally symmetrical marine fishes, in principle, are able to feel the difference between the static displacement of the large and small paired otoliths.

Why do flatfish otolith organs not rotate within the skull, as the eyes do, so that the otoliths retain their individual structural orientation relative to dorsal fin? This design in adult flatfishes produces an unusual orientation relative to the ocean bottom in comparison to roundfishes (Fig. 1). Calculations show that this unique orientation provides optimal scope for determining the direction of a sound source in the vertical plane, which may be very useful for bottomadapted adult animals [Fig. 1(b)]. Thus, it may be that the saccular otoliths in flatfishes retain their orientation relative to dorsal fin to determine the elevation (angles in the vertical plane), whereas roundfishes are designed to determine the azimuth (angles in the horizontal plane) [Fig. 1(b)]. It is worth noting the observation of Russian naturalists: 'In case of impending danger, flatfish turns on an edge with dorsal fin upwards, and as a lightning quickly swims forward then again turns by the blind side to the bottom and lies on the bottom' (Ostroumova, 1971). If this is so, the retention of the standard structural orientation of flatfish otoliths may be of great importance for postural adjustment during this escape reaction.

In conclusion, gaining a complete understanding of the causes of unusual sacculus orientation and blind-side otolith mass prevalence requires extended physiological, morphological and field investigations. There is a need to 
increase the amount of sampling (it especially concerns Soleidae) to fully apprehend the specific otolith mass relations in the individual species. It concerns the otolith shape as well. It is well known that otolith shape is very labile and can be a good population characteristic. On the other hand, mathematical modelling shows that the otolith shape variability can be of adaptive significance and can be caused by the need to tune the otolith organs to the predominant recognition of specific (relative head) sound directions (Lychakov \& Rebane, 1993). The problem of otolith shape asymmetry, however, has been poorly investigated. In addition, it will be very interesting to compare the otolith mass asymmetry before and after metamorphosis.

This work was partly supported by Russian RFFI 05-04-48303 grant, Russian St Petersburg Scientific Centre Programme and the EU Project RESPONSE (contract Q5RS-2002-00787). The authors thank E. Visauta, A. Bucci, A. Cruz, C. Coll and I. Olabarrieta for their support in the sampling process and the participants of the RESPONSE and BENSED projects.

\section{References}

Campana, S. E. (2004). Photographic atlas of fish otoliths of the Northwest Atlantic Ocean. Canadian Special Publication of Fisheries and Aquatic Sciences 133.

Chapman, C. J. \& Johnstone, A. D. F. (1974). Some auditory discrimination experiments on marine fish. Journal of Experimental Biology 61, 521-528.

Chapman, C. J. \& Sand, O. (1974). Field studies of hearing in two species of flatfish Pleuronectes platessa (L.) and Limanda limanda (L.) (Family Pleuronectidae). Comparative Biochemistry and Physiology A 74, 371-385.

Dale, T. (1976). The labyrinthine mechanoreceptor organs of the cod Gadus morhua L. (Teleostei: Gadidae). Norway Journal of Zoology 24, 85-128.

De Vries, H. L. (1950). The mechanics of the labyrinth otoliths. Acta Otolaryngology (Stockholm) 38, 262-273.

Egorov, A. D. \& Samarin, G. I. (1970). Possible change in the paired operation of the vestibular apparatus during weightlessness. Kosmicheskaya Biologiya i Aviakosmicheskaya Medicina 4, 85-86 (in Russian).

Fay, R. R. \& Popper, A. N. (1980). Structure and function in teleost auditory systems. In Comparative Studies of Hearing in Vertebrates (Popper, A. N. \& Fay, R. R., eds), pp. 3-42. New York: Springer-Verlag.

Goldberg, J. M. \& Fernández, C. (1975). Vestibular mechanisms. Annual Review of Physiology 37, 129-162.

Graf, W. \& Baker, R. (1990). Neuronal adaptation accompanying metamorphosis in the flatfish. Journal of Neurobiology 21, 1136-1152.

Helling, K., Scherer, H., Hausmann, S. \& Clarke, A. H. (2005). Otolith mass asymmetries in the utricle and saccule of flatfish. Vestibular Research 15, 59-64.

Hoffman, R. B., Salinas, G. A. \& Baky, A. A. (1977). Behavioral analyses of killifish exposed to weightlessness in the Apollo-Soyuz test project. Aviation Space and Environmental Medicine 48, 712-717.

Hudspeth, A. J. \& Corey, D. P. (1977). Sensitivity, polarity and conductance change in the response of vertebrate hair cells to controlled mechanical stimuli. Proceedings of the National Academy of Science of the USA 74, 2407-2411.

Lombarte, A. \& Morales-Nin, B. (1995). Morphology and ultrastructure of saccular otoliths from five species of the genus Coelorinchus (Gadiformes: Macrouridae) from the Southeast Atlantic. Journal of Morphology 225, 179-192.

Lombarte, A., Chic, Ò., Parisi-Baradad, V., Olivella, R., Piera, J. \& García-Ladona, E. (2006). A web-based environment from shape analysis of fish otoliths. The AFORO database. Scientia Marina 70, 147-152. 
Lu, Z., Song, J. \& Popper, A. N. (1998). Encoding of acoustic directional information by saccular afferents of the sleeper goby, Dormitator latifrons. Journal of Comparative. Physiology A 182, 805-815.

Lychakov, D. V. (1996). Anomalous otoliths of the Black Sea fishes. Journal of Evolutionary Biochemistry and Physiology 32, 385-391.

Lychakov, D. V. \& Rebane, Y. T. (1993). Effect of otolith shape on directional sound perception in fishes. Journal of Evolutionary Biochemistry and Physiology 28, 531-536.

Lychakov, D. V. \& Rebane, Y. T. (2000). Otolith regularities. Hearing Research 143, $83-102$.

Lychakov, D. V. \& Rebane, Y. T. (2004). Otolith mass asymmetry in 18 species of fish and pigeon. Journal of Gravity Physiology 11, 17-34.

Lychakov, D. V. \& Rebane, Y. T. (2005). Fish otolith mass asymmetry: morphometry and influence on acoustic functionality. Hearing Research 201, 55-69.

Lychakov, D. V., Rebane, Y. T., Lombarte, A., Fuiman, L. A. \& Takabayashi, A. (2006). Fish otolith asymmetry: morphometry and modeling. Hearing Research 219, 1-11.

Nolf, D. (1985). Otolith piscium. In Handbook of Paleoichthyology, Vol. 10 (Schultze, H. P., ed.), pp. 1-145. Sttutgart: Gustav Fisher Verlag.

Ohmori, H. (1987). Gating properties of the mechano-electrical transducer channel in the dissociated vestibular hair cell of the chick. Journal of Physiology 387, 589-609.

Ostroumova, T. A. (1971). Flatfishes (Pleuronectiformes). In The Life of Animals, Vol. 4 (Rass, T. S., ed.), pp. 582-591. Moscow: Prosveshenie (in Russian).

Platt, C. (1973). Central control of postural orientation in flatfish. I. Postural change dependence of central neural changes. Journal of Experimental Biology 59, 491-521.

Popper, A. \& Carlson, T. J. (1998). Application of sound and other stimuli to control fish behavior. Transactions of American Fisheries Society 127, 673-707.

Popper, A. \& Fay, R. R. (1993). Sound detection and processing by fish: critical review and major research questions. Brain, Behaviour and Evolution 41, 14-38.

Rogers, P. H., Popper, A. N., Hastings, M. C. \& Saidel, W. M. (1988). Processing of acoustic signals in the auditory system of bony fish. Journal of the Acoustical Society of America 83, 338-349.

Sand, O. (2002). Sound source location: an historical assessment. Bioacoustics 12, 199-201.

Schreiber, A. M. (2006). Asymmetric craniofacial remodeling and lateralized behavior in larval flatfish. Journal of Experimental Biology 209, 610-621.

Schujf, A. \& Buwalda, R. J. A. (1980). Underwater localization - A major problem in fish acoustics. In Comparative Studies of Hearing in Vertebrates (Popper, A. N. \& Fay, R. R., eds), pp. 43-77. New York: Springer-Verlag.

Sogard, S. M. (1991). Interpretation of otolith microstructure in juvenile winter flounder (Pseudopleuronectes americanus): ontogenetic development, daily increment validation, and somatic growth relationships. Canadian Journal of Fisheries and Aquatic Sciences 48, 1862-1871.

Von Baumgarten, R. J., Wetzig, J., Vogel, H. \& Kass, J. R. (1982). Static and dynamic mechanisms of space vestibular malaise. Physiologist 25 (Suppl.), 33-36.

Wysocki, L. E. \& Ladich, F. (2002). Can fishes resolve temporal characteristics of sound? New insights using auditory brainstem responses. Hearing Research 169, 36-46. 